\title{
Gaining advantage by winning contests
}

\section{Derek J. Clark ${ }^{1} \cdot$ Tore Nilssen $^{2}$ (D) Jan Yngve Sand ${ }^{1}$}

Received: 3 November 2019 / Accepted: 10 March 2020 / Published online: 20 March 2020

(c) The Author(s) 2020

\begin{abstract}
We consider a principal who faces many identical competitors, and who can distribute a prize fund over two consecutive contests. The winner of contest one gains an advantage in contest two where his effort is more productive than all rivals. We identify a tipping point for the productivity parameter, below which it is optimal for an effort-maximizing principal to place the whole prize in the second contest. Above this level, a single symmetric contest is preferred. The institution chosen depends inextricably upon the number of competitors and their valuation of future gains and costs. We identify the optimal setting of the productivity parameter, showing that introducing asymmetry can increase total efforts by as much as one quarter compared to a single symmetric contest.
\end{abstract}

Keywords Contest $\cdot$ Win advantage $\cdot$ Effort incentives $\cdot$ Budget division

JEL Classification D74 · D72

\begin{abstract}
We are grateful to participants at various seminars and workshops for comments. We are grateful for the insightful comments of two anonymous referees, an Associate Editor, and the Editor Huseyin Yildirim. Errors are our own. Nilssen has received funding for his research through the ESOP Centre at the University of Oslo. ESOP received support from the Research Council of Norway through its Centres of Excellence funding scheme, Project Number 179552.
\end{abstract}

$凶$ Tore Nilssen

tore.nilssen@econ.uio.no

Derek J. Clark

derek.clark@uit.no

Jan Yngve Sand

jan.sand@uit.no

1 School of Business and Economics, UiT - The Arctic University of Norway, 9037 Troms $\varnothing$, Norway

2 Department of Economics, University of Oslo, P.O. Box 1095, 0317 Oslo, Blindern, Norway 


\section{Introduction}

Many contest situations have the features that (i) contestants meet more than once, (ii) winning in early rounds gives an advantage in later rounds, and (iii) the prize structure is such that the prize value in each stage differs.

Contest designers interested in keeping up overall efforts among contestants in such situations may be concerned with win advantages potentially creating discouragement among early losers, at the same time as they would like to take advantage of the increased efficiency of early winners. In this paper, we set up a model to study such a contest situation and the contest designer's optimum decision. In the model, there are two simple Tullock contests run in sequence among the same set of players, and the winner of the first contest has an advantage over the other players in the second one. The win advantage is such that the winner of the first contest has more productive efforts than the others in contest two, effectively biasing the probability of winning the second contest in favour of the early winner. ${ }^{1}$

The win advantage from the early round introduces an asymmetry into the subsequent competition which was not there at the start. The effort-maximizing contest designer has available a prize fund of fixed size that she can freely allocate between the two contests. We find conditions under which the optimum for the designer is to put the whole prize fund in the second contest, so that the first contest is merely a token one where the contestants fight purely for the win advantage. We identify a tipping point for the bias parameter, below which this is the optimal policy for the designer. Giving one contestant a positive bias in the second-period contest success function will affect the best response functions of all players; the advantaged player can exert less effort than in the symmetric case and still win with a high probability, whilst the disadvantaged also reduce effort to save cost. In order to inspire effort in the biased contest, the designer must give a large prize. Hence, when the win advantage from the first contest translates into a biased contest success function in the second, the players must be sufficiently incentivized to induce effort by the promise of a high prize. If the bias is too large however, the discouragement effect cannot be overcome, and the principal will run a single symmetric contest.

Our model can find application in a wide range of areas, for example research funding, sales force (and general personnel) management, elections and sports. Consider the choice facing research councils when deciding how to distribute prize funds for a research programme over several rounds. Here we would think of "effort" by competitors as resources spent building up a research team which would make a good application credible, rather than the amount of time spent writing an application. It has been argued that there is a sizeable win advantage in science, dubbed a Matthew Effect by Merton (1968). According to Gallini and Scotchmer (2002, p. 54), competing for grants is easier for those who have won previously: "[F]uture grants are contingent upon previous success. The linkage between previous success and future funding seems even more specific in the case of the National Science Council". The principal,

\footnotetext{
1 Two types of discrimination in contests are discussed by Mealem and Nitzan (2016). Direct discrimination occurs when the value of the prize is changed for one or more competitors, and structural discrimination when parameters in the contest success function are changed. We show below that our model captures both of these situations.
} 
in this case a research council, may wish competitors to have most effort later on in order to allow the participating research teams to exploit the enhanced efficiency or productivity from the win advantage. Balancing this concern against the potential discouragement among non-winning research teams, our analysis shows that the research council would usually like to have the big research money late in the programme.

Sequences of contests are also in frequent use in promotion or hiring competitions where candidates must perform different tasks, and winning gives a benefit at the next stage. In sales-force management, one finds seller-of-the-month awards and the like in order to provide motivation for the sales force. In such settings, it is not uncommon for the more successful agents to be given less administrative duties, better access to back-office resources, more training than the less successful, and better territories; see, e.g., Skiera and Albers (1998), Farrell and Hakstian (2001), and Krishnamoorthy et al. (2005). These factors may increase the successful salesperson's efficiency in the competition. A common feature of political elections are television debates where candidates face each other and the audience gets information on their policies and other relevant attributes. Indeed, Schrott (1990) suggests that the winner of a pre-election TV debate may be seen as obtaining a win advantage in the ensuing election. In a quite different setting, students are subject to a number of tests throughout the year, with the final ranking being based on an exam in the end. In sports, the win advantage may be founded on psychological or physiological factors (Krumer 2013). Cohen-Zada et al. (2017) find a significant psychological advantage in men's professional judo competitions; they link this to biological literature in which performance-enhancing testosterone increases following victory and falls after defeat. Evidence pointing to the presence of a win advantage in sequential competition is found in experimental studies carried out by Reeve et al. (1985) and Vansteenkiste and Deci (2003). These studies show that winners feel more competent than losers, and that winning facilitates competitive performance and contributes positively to an individual's intrinsic motivation. $^{2}$

The study closest to ours is that of Möller (2012). Like us, he posits a sequence of contests in which the principal can choose how to distribute the prize fund across the contests. His win advantage differs from ours, though, since his contest designer can use prizes to fine-tune the amount of heterogeneity between competitors in the second contest. He posits a smooth relationship between the first-contest prize and the ability to compete in the second period, so that a designer can choose exactly which types of player compete in the second contest. Such power is often out of the scope of a contest designer. Our model captures a situation where there is a discrete advantage from winning, and where a loser gains nothing. Moreover, the size of the win advantage in our model is not related to the size of the prize on offer in the first contest; a psychological advantage of beating an opponent is, for example, not necessarily related to the immediate prize. This simplification means that our work easily extends to many players, whereas contest design in Möller (2012) would be difficult in this case.

\footnotetext{
2 See otherwise the discussion in Clark and Nilssen (2020) regarding the pyschological and physiological reasons for a win advantage in competitions.
} 
The win advantage in the work of Megidish and Sela (2014) is, on the other hand, more similar to ours. They consider a fixed contest structure in which two players compete for two identical prizes that are awarded in each of two rounds; the players' valuations of the prizes differ initially, and the value that the winner of the first prize attaches to the second is either reduced or increased compared to the first. Hence winning may be a disadvantage or an advantage. The loser values the prize equally in both rounds. Megidish and Sela (2014) focus on the effect that budget constraints have on the intertemporal decisions of the contestants, as well as the interplay between the budget constraint and the marginal valuations. One important result is that a contest designer would prefer the two contestants to have increasing valuations (i.e. a win advantage) when the budget constraint does not bind. Our model indicates a limitation to this argument, since we find conditions under which the designer would prefer to shut down the second contest entirely. The effect of the win advantage can be enhanced or neutralized by the designer in our framework, whereas it is fixed in Megidish and Sela (2014). Furthermore, our formulation facilitates a transparent analysis of the case of $n$ players, as well as calculation of the optimal size of the win advantage if this can be chosen by the principal.

Also related is the study of Beviá and Corchón (2013), who look at the evolvement of strength in two sequential contests with identical prizes. The initial Tullock probability function (interpreted by the authors as a share) is augmented with a weight for each of two players showing ex-ante strength. The share of the prize gained by a player in the first contest translates into a strength in the second one by an increasing transition function. ${ }^{3}$ Conditions are presented under which (i) the weaker player in the first contest will become even weaker in the second (dubbed the avalanche effect), and (ii) the weaker player will get a lower share of the prize over time (the domino effect). Luo and Xie (2018) consider a direct extension of Beviá and Corchón (2013) by allowing the contestable prize to be endogenous in the sense that the prize on offer is reduced by the efforts of the rivals. This modification eliminates the possibility of the avalanche and domino effects. The intuition is that effort effectively costs the stronger player more since this reduces the size of the contestable prize and he expects to win a larger share of it; hence the weaker player has larger effort in the first contest which implies that he does not get weaker or a snaller share over time. Since effort influences the share of the prize in a continuous way, and the share then increases the strength continuously, Beviá and Corchón (2013) and Luo and Xie (2018) are more similar to Clark and Nilssen (2013), who consider a direct correspondence between current effort and the effort cost in a subsequent contest. Schmitt et al. (2004), Casas-Arce and Martínez-Jerez (2009), Grossmann and Dietl (2009), and Sela (2017) also discuss such dynamic effort effects, whereby early efforts create later advantages. ${ }^{4}$ In Kovenock and Roberson (2009), it is the net effort, i.e., a winner's effort over and above that of the other player's effort, that creates an advantage in a later contest. Yildirim (2005) looks at a single contest in which efforts can be made over two rounds before the winner is decided; first-round efforts are observed before second-round efforts are made.

\footnotetext{
3 The equilibrium with two-players is symmetric, whereas this feature does not hold in an $n$-player model.

4 To be precise: either advantages or disadvantages, in the case of Sela (2017).
} 
More generally, our work is related to studies of dynamic battles; see the survey by Konrad (2009, ch 8). One such battle is the race, in which there is a grand prize to the player who first scores a sufficient number of wins. A related notion is the tug-of-war, where the winner of the grand prize is the one who first gets a sufficiently high lead. Early formal analyses of the race and the tug-of-war were done by Harris and Vickers (1987). A study of a race where there, as in our model, also are intermediate prizes in each round, in addition to the grand prize of the race, is Konrad and Kovenock (2009).

Another variation of a dynamic battle is the elimination tournament, where the best players in an early round are the only players proceeding to the next round. Thus, in an elimination tournament, the number of players decreases over time. Although this is a setting very different to ours, similar issues are investigated. Both Rosen (1986) and $\mathrm{Fu}$ and $\mathrm{Lu}$ (2012) find, in line with our result, that it is optimal for the contest designer to put the prize mass towards the end of the tournament. Delfgaauw et al. (2015) correspondingly find, in a field experiment, that increasing late prizes leads to higher total effort.

Mago et al. (2013) find that intermediate prizes increase efforts of both winner and loser in their theoretical and experimental analyses. This is contrary to our finding that it is optimal to shift prizes to the final round. However, in their work there is no win advantage. Krumer (2013) and Clark and Nilssen (2018, 2019, 2020) carry out analyses related to ours, where each stage contains an all-pay auction with a win advantage, whereas the present analysis is based on a Tullock contest at each stage. Klein and Schmutzler (2017) analyze a series of contests in which the effort in each period may be weighted when deciding on the final prize. They show, in line with our results, that the bulk of the prize mass should be distributed to the final round.

For the most part, our analysis concerns a setting where the win advantage is exogenous while the prize distribution across contests is decided by the principal. Still, there is a clear link to the analyses of Meyer (1992), Ridlon and Shin (2013), Franke et al. (2013), and Franke et al. (2018) who discuss situations where the size of the win advantage, and therefore the asymmetry between players in the second contest, is decided upon by a contest designer. Similarly, Esteve-González (2016) shows, in a setting with repeated services procurement, that mitigation of a moral hazard problem in service provision may be achieved through introducing a bias in the second period contest based on past performance. Barbieri and Serena (2018) consider a best-of-three Tullock model in which the principal may change the bias at each stage, showing that the optimal scheme is victory dependent; this resembles the win advantage that we consider here. Their analysis concerns designing the structure of the game for a fixed prize, whereas our model also considers the optimal prize split.

In line with this literature, we extend our analysis to also investigate the possibility that the principal may be able to design the competition in order to specify the exact size of the asymmetry in the second contest. We derive results for the optimal level of bias in this case for an effort-maximizing principal in the n-player framework, calculating also the proportional gain to using the optimal asymmetric dynamic contest as compared to a simple symmetric one. When the bias is an instrument under the control of the principal, one can also consider how incentives can be given to the first contest leader to exert high effort in the second contest. A research council may want the leading team to exert extra effort to become world-leading for example; this resembles the 
quality contest of Serena (2017), and we calculate the optimal bias set by the principal who wants maximum effort from the leader in the second contest. Here again there is an important difference between the case of two players and more. With two players, the equilibrium of the second contest is symmetric, and the principal cannot incite the leader to exert more effort by increasing the bias since the symmetric effort level achieves a greater than one half chance of winning. With more competitors, this effect is weakened, since the leader must beat many rivals, and simply having the effort of all others gains little in terms of extra probability of winning. The more rivals that must be beaten, the greater must be the bias in order to incentivize effort from the leader.

The paper is organized as follows. In Sect. 2, we present the model. In Sect. 3, we present the analysis of the model and our main results on the principal's optimum distribution of the prize fund across the contests, as well as the optimal bias when this is an instrument under the command of the principal. Section 4 concludes.

\section{Model}

Consider a set $N$ of $n \geq 2$ players who compete with each other in two interlinked sequential contests. The players compete by making non-refundable outlays and determine their efforts in each contest, each with the aim to maximize own expected payoff. Players are assumed to discount future payoffs with a discount factor $\delta \in(0,1]$. A principal has a prize mass of size one, and distributes $1-v$ of this in contest one, and $v$ in contest two, where $v \in[0,1] .^{5}$

Let $x_{i, t}$ be the effort exerted by player $i$ in contest $t$, and let $p_{i, t}$ be the probability that player $i$ wins it, where $i \in N$ and $t \in\{1,2\}$. The marginal cost of effort is constant at one for all players in both contests. In contest one, the winner is determined by a regular Tullock contest success function: ${ }^{6}$

$$
p_{i, 1}=\left\{\begin{array}{ll}
\frac{x_{i, 1}}{\sum_{j=1}^{n} x_{j, 1}} & \text { if } \sum_{j=1}^{n} x_{j, 1} \neq 0 \\
\frac{1}{n} & \text { if } \sum_{j=1}^{n} x_{j, 1}=0
\end{array} .\right.
$$

The winner of the first contest obtains an advantage before contest two; specifically, his efforts in contest two are more productive than all opponents. If player $i \in N$ wins contest one, then he has an input to the Tullock contest success function of contest two of $\beta x_{i, 2}$, where $\beta \geq 1$ is a favorable bias that multiplies up the contestant's effort in contest two. We have that

\footnotetext{
5 Fixing the prize mass at 1 is without loss of generality. The trade off between an early and late prize is unaffected by this, as can be seen from (13) which is the expression for total effort in the first contest. Replacing the first 1 by $V>1$ increases first contest effort, but does not affect the decision as to whether $v$ should be large $(v=V)$ or small $(v=0)$.

6 As axiomatized by Skaperdas (1996) and Clark and Riis (1998) and used in numerous contest applications; see, for example, Konrad (2009).
} 


$$
\begin{aligned}
& p_{i, 2}=\rho_{i}(i)=\frac{\beta x_{i, 2}}{\beta x_{i, 2}+\sum_{k=1, k \neq i}^{n} x_{k, 2}}, \\
& p_{j, 2}=\rho_{j}(i)=\frac{x_{j, 2}}{\beta x_{i, 2}+\sum_{k=1, k \neq i}^{n} x_{k, 2}}, i, j \in N, j \neq i
\end{aligned}
$$

where $\rho_{j}(i)$ denotes the win probability of player $j$ in contest two after player $i$ has won contest one. ${ }^{7}$

Note that the winner of contest one gains an advantage in contest two that is associated with the act of winning and not with the margin of victory. A one-shot contest using a form similar to (2) has been investigated by Franke et al. (2013) and Franke et al. (2018). Beviá and Corchón (2013) investigate a two-player model in which the outcome of the first contest affects contestants' strength in a second contest. There, the bias parameters of the players evolve continuously according to the probability that each rival wins the first contest. Möller (2012) has continuous cost adjustment between two contests in his two-player model. Our approach emphasizes the winner-take-all nature of contests.

In contest two, suppose that player $i$ has won the first. Then the expected payoff of this player, denoted $\pi_{i, 2}(i)$, and of the $n-1$ losers, $\pi_{j, 2}(i)$, are

$$
\begin{aligned}
& \pi_{i, 2}(i)=\rho_{i}(i) v-x_{i, 2} ; \text { and } \\
& \pi_{j, 2}(i)=\rho_{j}(i) v-x_{j, 2}, j \neq i .
\end{aligned}
$$

Note that the problem in (3) can be transformed by setting $z_{i, 2}(i)=\beta x_{i, 2}$, so that

$$
\pi_{i, 2}(i)=\frac{z_{i, 2}}{z_{i, 2}+\sum_{k=1, k \neq i}^{n} x_{k, 2}} v-\frac{z_{i, 2}}{\beta} .
$$

Hence, measuring the win advantage as affecting the contest success function (Beviá and Corchón 2013) or the cost of effort [Möller (2012)] are equivalent approaches. ${ }^{8}$

Turning attention to contest one, the expected payoffs of the players are identical, since all players are identical and have the same possibility of winning contest one. Let $\pi_{k, 2}^{*}(k)$ denote the expected payoff in contest two for player $k$ given that he has won contest one; also $\pi_{k, 2}^{*}(j)$ is the expected contest two payoff of player $k$ when another player $(j)$ has won the first contest. The expected payoff function for player $k$ is

$$
\pi_{k, 1}=p_{k, 1}\left[1-v+\delta \pi_{k, 2}^{*}(k)\right]+\left(1-p_{k, 1}\right) \delta \pi_{k, 2}^{*}(j)-x_{k, 1}, k \neq j,
$$

where $p_{k, 1}$ is given by (1). Winning the first contest yields an immediate benefit of the stage prize $1-v$, but also the promise of the discounted leader payoff $\pi_{k, 2}^{*}(k)$

\footnotetext{
7 This assumes again that $\beta x_{i, 2}+\sum_{k=1, k \neq i}^{n} x_{k, 2} \neq 0$. If this is violated, all players have a $\frac{1}{n}$ chance of winning; the winner must hence make a positive effort to gain from the win advantage since it enhances his productivity.

8 We would like to thank a referee for pointing this out to us.
} 
in contest two. Losing the first contest gives no stage prize, only the promise of the discounted loser payoff in contest two; we show below that this guaranteed payoff is lower, the larger the win advantage.

\section{Analysis}

We study the subgame-perfect equilibrium of our game and are interested in finding conditions under which the principal prefers to run two contests rather than one. In the two-contest framework, one contestant becomes more efficient at exerting effort in contest two, which may be expected to reduce own effort and discourage rivals. On the other hand, all players will compete intensely to gain this advantage at the first contest stage. The principal can divide her budget over the two contests to induce as much effort as possible, given that this leads to more than a single contest. Let $X^{*}(v)$ denote the total expected effort, and define

$$
\widetilde{\beta}(\delta, n)=: \frac{(n-1)-\delta(n-3)}{(n-1)(1-\delta)} .
$$

The following proposition gives the main result. ${ }^{9}$

Proposition 1 The contest has a unique subgame-perfect equilibrium. In this equilibrium the effort-maximizing principal sets

(i) $v=0$ if $\beta \geq \widetilde{\beta}(\delta, n)$, with total effort $X^{*}(0)=\frac{n-1}{n}$; and

(ii) $v=1$ if $1<\beta<\widetilde{\beta}(\delta, n)$, obtaining total effort

$$
X^{*}(1)=\frac{n-1}{n}\left(\frac{\delta(\beta-1)(n-1)[\beta(n-1)-(n-3)]+2 n(n-1) \beta-n(n-2)}{[1+\beta(n-1)]^{2}}\right) .
$$

Proof Let $X_{t}^{*}(v)$ denote total equilibrium efforts in contest $t \in\{1,2\}$. It follows from Franke et al. (2013) that contest two has a unique Nash equilibrium. We calculate this from the first-order conditions of (3) and (4). Equilibrium efforts in contest two thus are: ${ }^{10}$

$$
\begin{aligned}
& x_{i, 2}^{*}(i)=\frac{\beta(n-1)-(n-2)}{[1+\beta(n-1)]^{2}}(n-1) v ; \\
& x_{j, 2}^{*}(i)=\frac{\beta}{[1+\beta(n-1)]^{2}}(n-1) v, \quad j \neq i
\end{aligned}
$$

\footnotetext{
9 When $\beta=1$, both contests are symmetric, and any $v \in[0,1]$ gives the same amount of effort, $\frac{n-1}{n}$ in total.

10 Note that, since the identical losers behave identically in the unique equilibrium of contest two, this equilibrium satisfies type symmetry as defined in Sahi and Yao (1989). It follows that the unique subgameperfect equilibrium of the full game also features type symmetry.

Note also that players' second-order conditions in contest two are satisfied:
} 


$$
X_{2}^{*}(v)=\frac{2 \beta(n-1)-(n-2)}{[1+\beta(n-1)]^{2}}(n-1) v .
$$

The condition for full participation in Franke, et al. (2013, Theorem 2.3) is fulfilled; a zero effort by a player gets zero in payoff if any rival has positive effort, whereas expected equilibrium payoffs for the contest-one winner and the losers, respectively, in the second contest are positive:

$$
\begin{aligned}
& \pi_{i, 2}^{*}(i)=\left(\frac{\beta(n-1)-(n-2)}{1+\beta(n-1)}\right)^{2} v ; \\
& \pi_{j, 2}^{*}(i)=\left(\frac{1}{1+\beta(n-1)}\right)^{2} v, j \neq i ;
\end{aligned}
$$

where, clearly, $\pi_{i, 2}^{*}(i) \geq \pi_{j, 2}^{*}(i)$, implying that there is in fact a value in contest two to being the winner in contest one; indeed, this value is larger the larger is the contest-two prize $v$.

It follows from Franke et al. (2013) and the definition of subgame perfectness that the full game has a unique subgame-perfect equilibrium, which is symmetric, or rather type symmetric, since all players are identical ex ante. ${ }^{11}$ In this equilibrium, total effort in contest one is

$$
X_{1}^{*}(v)=\frac{n-1}{n}\left(1-v+\frac{\delta(\beta-1)(n-1)[\beta(n-1)-(n-3)]}{[1+\beta(n-1)]^{2}} v\right) .
$$

Again, unilaterally submitting zero in effort in the first contest gives an expected payoff equal to $\delta \pi_{j, 2}^{*}(i)$ in (12), whereas the equilibrium strategy yields

$$
\pi_{1}^{*}=\frac{1}{n^{2}}\left(1-\left(1-\delta \frac{[\beta(n-1)-(n-2)]^{2}+\left(n^{2}-1\right)}{[1+\beta(n-1)]^{2}}\right) v\right)
$$

Footnote 10 continued

$$
\begin{aligned}
& \frac{\partial^{2} x_{i, 2}(i)}{\partial\left(x_{i, 2}(i)\right)^{2}}=-\frac{2 \beta^{2} \sum_{k \neq i}^{n} x_{k, 2}(i)}{\left[\beta x_{1}+\sum_{k \neq i}^{n} x_{k, 2}(i)\right]^{3}}<0, \text { and } \\
& \frac{\partial^{2} x_{j, 2}(i)}{\partial\left(x_{j, 2}(i)\right)^{2}}=-\frac{2\left[\beta x_{i, 2}(i)+\sum_{k \neq i, k \neq j}^{n} x_{k, 2}(i)\right]}{\left[\beta x_{i, 2}(i)+\sum_{k \neq i}^{n} x_{k, 2}(i)\right]^{3}}<0, j \neq i .
\end{aligned}
$$

11 Note that players' second-order conditions in contest one are satisfied since $p_{i, 1}$ in (1) is stricly concave in $x_{i, 1}$. See also the discussion in Pérez-Castrillo and Verdier (1992) which implies that the symmetric first contest has a unique equilibrium. 
A zero effort is dominated if $\pi_{1}^{*}>\delta \pi_{j, 2}^{*}(i)$, implying

$$
\begin{aligned}
\frac{1-v}{n^{2}}+\delta \frac{[\beta(n-1)-(n-2)]^{2}+\left(n^{2}-1\right)}{n^{2}[1+\beta(n-1)]^{2}} v & >\delta\left(\frac{1}{1+\beta(n-1)}\right)^{2} v \Leftrightarrow \\
\frac{1-v}{n^{2}}+\frac{\delta v(\beta-1)(n-1)[\beta(n-1)-(n-3)]}{n^{2}[1+\beta(n-1)]^{2}} & >0,
\end{aligned}
$$

which is clearly true, since $\beta \geq 1$.

Total effort in the $n$-player contest series is then given by

$$
\begin{aligned}
& X^{*}(v)=X_{1}^{*}(v)+X_{2}^{*}(v) \\
= & \frac{n-1}{n}\left(1+v \frac{Y(\beta, \delta, n)}{[1+\beta(n-1)]^{2}}\right),
\end{aligned}
$$

where

$$
Y(\beta, \delta, n):=(\beta-1)(n-1)[(\beta(n-1)-(n-3)) \delta-(\beta-1)(n-1)] .
$$

From (14), we see that total effort is linear in $v$. This implies that the principal's optimal choice of $v$ is either 0 or 1 , depending on the sign of $Y(\beta, \delta, n)$ in (15). The critical value of $\beta$ that delineates these two cases is easily established as $\widetilde{\beta}(\delta, n)$ in (6). Total expected effort is then recovered from (14) by inserting $v=0$ or 1 .

The proposition shows that $\widetilde{\beta}(\delta, n)$ represents a tipping point for the value of the win advantage. It is readily established that $\frac{\partial X_{1}^{*}(v)}{\partial \beta}>0$, and $\frac{\partial X_{2}^{*}(v)}{\partial \beta}<0$, so that a large $\beta$ incites effort in the first contest but discourages it in the second. The former effect dominates for low values of $\beta$, making it optimal for the principal to put the whole prize in the second contest, with $v=1$, so that the first one will be merely for position. ${ }^{12}$ As $\beta$ becomes larger, the discouragement effect on the losers of having such a dominant player in contest two outweighs the incitement to become the dominant player. In this case a single contest is optimal, with $v=0$. The tipping point is increasing in the discount factor and decreasing in the number of players: $\frac{\partial \widetilde{\beta}(\delta, n)}{\partial \delta}>0, \frac{\partial \widetilde{\beta}(\delta, n)}{\partial n}<0$. Attaching a higher value to the future makes two contests optimal for higher values of the win advantage. If the players do not discount the future $(\delta=1)$, then $\widetilde{\beta}(1, n) \rightarrow \infty$, making the two-contest series optimal for all values of the win advantage. The more competitors there are, the less likely it is that a dynamic framework will be used by the principal. Intuitively, the value of being the advantaged player in contest two is lower when there are more contestants to beat in that contest.

The equilibrium probability that the winner of contest one wins also the second contest is

$$
\rho_{i, 2}^{*}(i)=\frac{\beta(n-1)-(n-2)}{1+\beta(n-1)},
$$

\footnotetext{
12 A referee has alikened this to a situation in which the first contest represents an unpaid internship, and the second is the battle for a permanent job in the organization. The favoured intern may be given extra training or other benefits that will lead to a larger probability of succeeding.
} 
which is decreasing in $n$. Hence, models that focus on two players may tend to overstate the usefulness of a dynamic framework for the effort-maximizing principal. ${ }^{13}$

From (8) and (9), we see that the contest-one winner always exerts more effort in the second contest than a loser does. ${ }^{14}$ Furthermore, we have that

$$
\frac{\partial x_{i, 2}^{*}(i)}{\partial n}>0 \Leftrightarrow \beta>1+\frac{n-2}{n-1},
$$

so that, if the win advantage is large enough, then the second-contest effort of the first-contest winner is increasing in the number of competitors. The second-contest effort of each first-contest loser, in (9), is decreasing in $n$, but the total amount of efforts by all losers in contest two is still increasing in $n$. The combined effect is that total contest-two effort, in (10), is always increasing in $n$ whenever $v>0: \frac{\partial X_{2}^{*}(v)}{\partial n}>0$. Generally, the effect that the number of competitors has on total efforts in the first of a two-contest series is ambiguous. However, in the optimal two contest framework $(v=1)$, one can determine that $\frac{\partial X_{1}^{*}(1)}{\partial n}>0$ always for $n=2$, whilst $\frac{\partial X_{1}^{*}(1)}{\partial n}>0$ for $n>2$ if $\beta>\frac{n-4+\sqrt{(9 n-2)(n-2)}}{2(n-1)}:=\widehat{\beta}(n) \in[1,2)$.

Note the subtle effect that the number of players has on the second-contest effort of the first-contest winner in (8). When $n>2$, the effort of the first-contest winner is modified by a negative term that disappears for $n=2$; essentially, the effect stems from the fact that a contestant losing in contest one faces $(n-2)$ other such losers in contest two, in addition to the contest-one winner. Note also that, in the contest-two equilibrium, winner and loser efforts are identical for any $\beta \geq 1$ when $n=2$, but not otherwise.

Suppose, as in Franke et al. (2013) and Franke et al. (2018), that the principal can determine the amount of bias that is afforded the winner of the first contest in contest two. The following proposition determines the optimal level of the bias, and indicates the proportional gain that can be achieved by running an optimal two-contest series rather than a single contest.

Proposition 2 Suppose that the principal sets $v=1$. Then the effort-maximizing level of bias is

$$
\beta^{*}(\delta, n)=\frac{(1-\delta) n^{2}+(3 \delta-1) n-\delta}{(n-1)(n(1-\delta)+\delta)} \in(1,2)
$$

This gives a proportional increase in expected effort over the single contest of $\frac{\delta^{2}}{n(n+2 \delta-n \delta)} \in\left(0, \frac{1}{4}\right]$.

Proof The function $\beta^{*}(\delta, n)$ is the unique solution to $\frac{\partial X^{*}(1)}{\partial \beta}=0 ; X^{*}(1)$ is a strictly concave function of $\beta$ for $\beta<\bar{\beta}(\delta, n):=\frac{8 n \delta-2 \delta-2 n-3 n^{2} \delta+3 n^{2}}{2(n-1)(n+\delta-n \delta)}$, where it is easily

\footnotetext{
13 Recall that both Möller (2012) and Beviá and Corchón (2013) consider only $n=2$.

14 We have that $x_{i, 2}^{*}(i) \geq x_{j, 2}^{*}(i)$. This is because $\beta(n-1)-(n-2) \geq \beta$, which follows from our assumption that $\beta \geq 1$.
} 
verified that $\bar{\beta}(\delta, n)>\beta^{*}(\delta, n)$. Furthermore, $\widetilde{\beta}(\delta, n)>\beta^{*}(\delta, n)$, so that a series of two contests is preferred to a single contest. One can verify that $\frac{\partial \beta^{*}(\delta, n)}{\partial \delta}>0$, and $\frac{\partial \beta^{*}(\delta, n)}{\partial n}<0$. The lower bound for the optimal bias occurs for $n=2$ and $\delta \rightarrow 0$, whilst the upper bound is found for $\delta=1$ and $n \rightarrow \infty$. The maximal expected effort achieved is then recovered as

$$
X^{*}\left(1, \beta^{*}\right)=\frac{\left((1-\delta) n^{2}+2 \delta n+\delta^{2}\right)(n-1)}{n^{2}(n(1-\delta)+2 \delta)},
$$

and the proportional increase is then easily found as $\frac{X^{*}\left(1, \beta^{*}\right)-X^{*}(0)}{X^{*}(0)}$. The lower bound of this expression occurs for $\delta \rightarrow 0$, and the upper bound for $n=2, \delta=1$.

By choosing an optimal two-contest framework, where the first one is purely for position and the bias is optimally determined, the principal can increase the total expected effort by up to a factor of $\frac{1}{4}$ compared to the single contest. The highest increase occurs for the lowest number of competitors since the discouragement effect introduced by the asymmetry then is less prevalent. Introducing an asymmetry into the dynamic framework is optimal for all numbers of competitors, although the size of the bias is largest for $n=2$, falling as more players are added. As noted before, this is to limit the negative effect that the bias has on those who have lost the first contest.

Note that $\beta^{*}(\delta, n)$ actually maximizes $X^{*}(v)$ for any $v \in(0,1]$, although the attained effort will fall as $v$ is reduced. It might for example be the case that this principal is tied to a particular distribution of the budget over time, such as with a research council that is running a programme where funding is already decided. The principal can still use the results from Proposition 2 to maximize effort, by giving the winner of the first contest an optimal advantage in the second.

Having afforded the winner of the first contest an advantage, the principal may wish to see as much effort as possible from this leading player, rather than simply maximizing total effort in aggregate. ${ }^{15}$ A research council that has seen one team build a lead on others may wish this entity to increase its quality further by exerting effort, rather than taking the chance that it might want to slack off in the light of the previous win. A sales company will similarly wish its leading seller to use his advantage to make more sales. In this case it is natural for the principal to want to maximize the effort of the leader in contest two. This cannot be done when the only instrument at her disposal is the budget division, but is a distinct possibility when the principal can set the bias parameter in the second contest. Straightforward maximization of $x_{i, 2}^{*}(i)$ in (8) gives the following result:

Proposition 3 A principal who wishes to maximize the effort of the contest-two leader will optimally set the bias at $\beta^{* *}(n)=\frac{2 n-3}{n-1} \in[1,2)$.

There are essentially two effects on the winner's contest-two effort from an increase in the win advantage $\beta$. On one hand, such an increase means that the player needs less effort to obtain a certain probability of winning contest two, which tends to lower his

15 This is similar to the quality contest in Serena (2017). We are grateful to the Associate Editor for pointing this out to us. 
contest-two effort. On the other hand, the player gets more out of each unit of effort when $\beta$ increases, which tends to increase the player's effort. Proposition 3 shows how to balance the two effects.

Note again the role that the number of competitors plays in this result with $n=$ 2 being a special case. With two players, the equilibrium of the second contest is symmetric $x_{i, 2}^{*}(i)=x_{j, 2}^{*}(i)$, so that the leader does not use the advantage to exert more effort; he exerts as much effort as all other players, but has a larger probability of winning due to the bias. The principal can effectively neutralize this effect by running a symmetric second contest, which is then the same as holding a single symmetric contest. Hence, when there are two players, there is no scope for inciting the leader to effort by biasing the second contest. This changes for $n>2$ as the equilibrium of the biased second contest is no longer symmetric, and the effort of the leader is increasing in $\beta$ up until $\beta^{* *}(n)$. The optimal bias in this case is increasing in the number of competitors: $\frac{\partial \beta^{* *}(n)}{\partial n}>0$; the advantage that the leader has in terms of the probability of winning is largest when there are few competitors, becoming weaker as more rivals must be beaten in order to also win contest two. Hence, the principal must reinforce the incentive to exert effort by giving a larger and larger bias as the number of rivals increases.

\section{Conclusion}

In this paper we have discussed a sequence of two Tullock contests with an arbitrary number of ex ante symmetric players where there is a gain to a player in the second contest from winning the first. This is modelled as the favoured player becoming more efficient at exerting effort in the second contest, and this might be exogenously given, or it can be controlled and set by the contest organizer. We have focussed particularly on the contest designer's choice of how to split a fixed prize fund between the two contests. One important finding is that there is a tipping point for the introduced asymmetry; if it is too large, the principal prefers to run a single contest. For low enough levels of asymmetry, two interlinked contests are optimal with the whole prize being awarded in the second one. Hence, the first contest is fought only for position. The promise of gaining a favoured position in the next contest has interesting effects on the effort levels of competitors. When the bias is large, effort in the first contest is high; the second contest is, however, not intensely fought in this case since the leader uses his advantage to slack off compared to a symmetric situation, while rivals become discouraged since they now face a more efficient opponent. The latter effect is more pronounced the larger the number of competitors. We have shown that the usually analyzed case of two competitors can give quite different results than when the field of contestants is larger. This is also the case for a principal who is interested in maximizing the effort of the first contest winner; when $n=2$, the equilibrium of the second contest is symmetric, and the principal cannot gain extra effort by biasing this contest. As the number of competitors grows, the effect of the bias in the contest success function becomes smaller, and the principal must increase the bias to incentivize the first-contest winner. 
An exogenous bias can result from the first contest winner gaining a momentum of some sort, whether physiological, psychological or due to tangible advantages as discussed in the Introduction. On the other hand, it may be possible for the principal to set the size of the bias as part of the rules of the contest series. In this case, we have calculated the optimal amount of asymmetry that should be introduced in the dynamic framework. Compared to a single contest, the principal can optimally design the two contests in order to achieve an increase in expected effort of up to one quarter; this factor falls as the number of contestants increases. Endogenizing the bias can also be used to boost aggregate effort in the case that the prize division is already determined (as may be the case for a research council, for example).

The basic model is robust to a number of extensions. One can use a general Tullock contest success function, where, instead of (1), we would have

$$
p_{i, 1}=\frac{x_{i, 1}^{r}}{\sum_{j=1}^{n} x_{j, 1}^{r}},
$$

where $r>0$, with an equivalent modification of (2); the parameter $r$ is the elasticity of the odds, often referred to as the discriminatory power of the contest. Subject to restrictions ensuring the existence of a pure-strategy equilibrium, also in the asymmetric game in contest two, ${ }^{16}$ the analysis of such a model is qualitatively the same as the simpler case of $r=1$. It is well known that the level of effort in each contest between risk-neutral players with linear cost will still be linear in the prize available at that stage. Hence, the bang-bang nature of our solution will not be affected since total effort will be linear in the second contest prize. This is in contrast to Feng and Lu (2018), who investigate a three-contest framework in which a contestant is awarded a final prize dependent upon the number of stage contests won. When the discriminatory power is low, a winner-take-all contest is optimal in which the prize is awarded to the winner of two or three battles, and nothing to the loser. In this case, efforts have little effect on the probability of winning, and the principal should award a single large prize to incite efforts. When the discriminatory power is larger, Feng and Lu (2018) show that any positive number of wins should be rewarded; an early loser may be discouraged and offer low effort, but can be incentivized with a large enough prize for the next win combined with the fact that effort has a large effect on the probability of winning. The three-contest structure implies that an early loser may catch up the first-contest winner and have a chance of surpassing him. This cannot occur in our two-contest model. Solving dynamic contests that rely on the Tullock contest success function is often complicated unless one makes simplifying assumptions about the form of competition or the prize structure. Our model with win advantages does not seem possible to solve even for the case of three contests.

A further extension would be to allow loss disadvantages in addition to a win advantage. A loss disadvantage would mean negative effects on productivity from losing a contest. This is a common feature from biology termed the "winner effect" in which the male of the species experiences an increase in testosterone following a contest win,

16 See, e.g., Nti (1999). 
and a reduction following a loss. ${ }^{17}$ We have analyzed a model incorporating such loss disadvantages, and find that they work in much the same way as discounting, making contestants more concerned about current payoff, and therefore making the principal more interested in placing the prize fund in the first contest.

Acknowledgements Open Access funding provided by University of Oslo (incl Oslo University Hospital).

Open Access This article is licensed under a Creative Commons Attribution 4.0 International License, which permits use, sharing, adaptation, distribution and reproduction in any medium or format, as long as you give appropriate credit to the original author(s) and the source, provide a link to the Creative Commons licence, and indicate if changes were made. The images or other third party material in this article are included in the article's Creative Commons licence, unless indicated otherwise in a credit line to the material. If material is not included in the article's Creative Commons licence and your intended use is not permitted by statutory regulation or exceeds the permitted use, you will need to obtain permission directly from the copyright holder. To view a copy of this licence, visit http://creativecommons.org/licenses/by/4.0/.

\section{References}

Barbieri S, Serena M (2018) Biasing unbiased dynamic contests. Max Planck Institute for Tax Law and Public Finance Working Paper 2018-06

Beviá C, Corchón LC (2013) Endogenous strength in conflicts. Int J Ind Organ 31:297-306

Casas-Arce P, Martínez-Jerez FA (2009) Relative performance compensation, contests, and dynamic incentives. Manag Sci 55:1306-1320

Chase ID, Bartolomeo C, Dugatkin LA (1994) Aggressive interactions and inter-contest interval: How long do winners keep winning? Anim Behav 48:393-400

Clark DJ, Nilssen T (2013) Learning by doing in contests. Pub Choice 156:329-343

Clark DJ, Nilssen T (2018) Keep on fighting: dynamic win effects in all-pay auctions. Games Econ Behav 110:258-272

Clark DJ, Nilssen T (2019) Beating the Matthew effect: head starts and catching up in a dynamic all-pay auction. https://doi.org/10.2139/ssrn.3155280

Clark DJ, Nilssen T (2020) Creating balance in dynamic competitions. Int J Ind Organ 69:102578

Clark DJ, Riis C (1998) Contest success functions: an extension. Econ Theory 11:201-204

Cohen-Zada D, Krumer A, Shtudiner Z (2017) Psychological momentum and gender. J Econ Behav Organ 135:66-81

Delfgaauw J, Dur R, Non A, Verbeke W (2015) The effects of prize spread and noise in elimination tournaments: a natural field experiment. J Labor Econ 33:521-569

Esteve-González P (2016) Moral hazard in repeated procurement of services. Int J Ind Organ 48:244-269

Farrell S, Hakstian AR (2001) Improving salesforce performance: a meta-analytic investigation of the effectiveness and utility of personnel selection procedures and training interventions. Psychol Mark 18:281-316

Feng X, Lu J (2018) How to split the pie: optimal rewards in dynamic multi-battle competitions. J Pub Econ 160:82-95

Franke J, Kanzow C, Leininger W, Schwartz A (2013) Effort maximization in asymmetric contest games with heterogeneous contestants. Econ Theory 52:589-630

Franke J, Leininger W, Wasser C (2018) Optimal favoritism in all-pay auctions and lottery contests. Eur Econ Rev 104:22-37

Fu Q, Lu J (2012) The optimal multi-stage contest. Econ Theory 51:351-382

Gallini N, Scotchmer S (2002) Intellectual property: when is it the best incentive system? Innov Policy Economy 2:51-77

Grossmann M, Dietl HM (2009) Investment behavior in a two-period contest model. J Inst Theor Econ 165:401-417

Harris C, Vickers J (1987) Racing with uncertainty. Rev Econ Stud 54:1-21

17 See Chase et al. (1994). 
Klein AH, Schmutzler A (2017) Optimal effort incentives in dynamic tournaments. Games Econ Behav 103:199-224

Konrad KA (2009) Strategy and dynamics in contests. Oxford University Press, Oxford

Konrad KA, Kovenock D (2009) Multi-battle contests. Games Econ Behav 66:256-274

Kovenock D, Roberson B (2009) Is the 50-state strategy optimal? J Theor Polit 21:213-236

Krishnamoorthy A, Misra S, Prasad A (2005) Scheduling sales force training: theory and evidence. Int J Res Mark 22:427-440

Krumer A (2013) Best-of-two contests with psychological effects. Theory Decis 75:85-100

Luo Z, Xie X (2018) A model of rivalries with endogenous prize and strength. J Econ Behav Organ 152:215-223

Mago SD, Sheremeta RM, Yates A (2013) Best-of-three contest experiments: strategic versus psychological momentum. Int J Ind Organ 31:287-296

Mealem Y, Nitzan S (2016) Discrimination in contests: a survey. Rev Econ Des 20:145-172

Megidish R, Sela A (2014) Sequential contests with synergy and budget constraints. Soc Choice Welf 42:215-243

Merton RK (1968) The Matthew effect in science. Science 159:56-63

Meyer MA (1992) Biased contests and moral hazard: implication for career profiles. Ann d'Écon Stat 25(26):165-187

Möller M (2012) Incentives versus competitive balance. Econ Lett 117:505-508

Nti KO (1999) Rent-seeking with asymmetric valuations. Pub Choice 98:415-430

Pérez-Castrillo D, Verdier T (1992) A general analysis of rent seeking games. Pub Choice 73:335-350

Reeve J, Olson BC, Cole SG (1985) Motivation and performance: two consequences of winning and losing in competition. Motiv Emot 9:291-298

Ridlon R, Shin J (2013) Favoring the winner or loser in repeated contests. Mark Sci 32:768-785

Rosen S (1986) Prizes and incentives in elimination tournaments. Am Econ Rev 76:701-715

Sahi S, Yao S (1989) The non-cooperative equilibria of a trading economy with complete markets and consistent prices. J Math Econ 18:325-346

Schmitt P, Shupp R, Swope K, Cadigan J (2004) Multi-period rent-seeking contests with carryover: theory and experimental evidence. Econ Gov 5:187-211

Schrott PR (1990) Electoral consequences of 'winning' televised campaign debates. Pub Opin Q 54:567-585

Sela A (2017) Two-stage contests with effort-dependent values of winning. Rev Econ Des 21:253-272

Serena M (2017) Quality contests. Eur J Polit Econ 46:15-25

Skaperdas S (1996) Contest success functions. Econ Theory 7:283-290

Skiera B, Albers S (1998) COSTA: contribution optimizing sales territory alignment. Mark Sci 17:196-213

Vansteenkiste M, Deci EL (2003) Competitively contingent rewards and intrinsic motivation: Can losers remain motivated? Motiv Emot 27:273-299

Yildirim H (2005) Contests with multiple rounds. Games Econ Behav 51:213-227

Publisher's Note Springer Nature remains neutral with regard to jurisdictional claims in published maps and institutional affiliations. 